\title{
Optimum Size of On-Farm Reservoir using Dynamic Programming
}

\author{
Mithlesh Kumar ${ }^{1 *}$, SanjeebPaul ${ }^{1}$, Sudhindra N. Panda ${ }^{1}$ and B. Panigrahi \\ ${ }^{1}$ Agricultural and Food Engineering Department, Indian Institute of Technology, \\ Kharagpur-721 302, West Bengal, India \\ ${ }^{2}$ Department of Soil and Water Conservation Engineering, College of Agricultural \\ Engineering and Technology, Orissa University of Agriculture and Technology, \\ Bhubaneswar-751003, Odisha, India \\ *Corresponding author
}

\section{A B S T R A C T}

Uneven distribution pattern of monsoon rain and highly permeable soil type and poor rainwater management practices effect the crop yield. Also lands remain barren in winter

\begin{tabular}{|l|}
\hline Ke y w or d s \\
Dynamic programing, \\
Supplemental irrigation, \\
On-farm reservir, \\
Rainfed agriculture, \\
Water management
\end{tabular}
season due to lack of rainfall. A Dynamic Programing (DP) model is developed to allocate optimum supplemental irrigation to crop for receives maximum net annual return from the cropped area under land and water availability constraints in the OFR based rainfed agricultural system. This model requires soil data, crop data, meteorological data and different level of water management strategies as inputs. The model integrates the dynamics associated with the water released by supplemental irrigation from the OFR to the actual water utilized by the crops at farm level. It also takes into account the non-linear relationship of root growth, soil moisture dynamics for multiple crops and yield response to water deficit at various growth stages of the crops. Apply this model to $800 \mathrm{~m}^{2}$ fields that the optimum size of the OFR varies with the combination of the crop (rice or rice mustard) and the size of OFR reduces in $15 \%$ soil moisture depletion factor than $10 \%$ soil moisture depletion factor also the OFR size is less for rice than rice - mustard scenario. For $10 \%$ soil water depletion for rice (from saturation) and mustard (from field capacity) crops, the optimum size of OFR varied from $5.35 \%$ to $9.85 \%$. Similarly, for $15 \%$ soil water depletion it varied from $5.05 \%$ to $9.35 \%$.

\section{Introduction}

The on-farm reservoir (OFR) is a small storage structure constructed for collecting surface runoff from the field. The design of the OFR consists of finding a suitable combination of surface area, depth of storage and a permissible side slope for a given storage volume. The on-farm reservoir (OFR) designed for harvesting and recycling of rainwater for rice based cropping pattern in rainfed lowlands (Srivastava, 2001; Islam et al., 1998) and uplands (Panigrahi et al., 2007) appears to be a full proof technology for enhancing rice production during drought years. But the technology is not sound enough to guarantee optimum yield from winter crops. Because, a rice crop cultivated at the upstream of the reservoir obstructs a large amount of runoff to maintain its depth of ponding 
requirement and also requires equally enough water as supplemental irrigation during its critical growth stage. This is the reason why the reservoir lacks adequate storage for meeting the irrigation requirement of winter crops. Out of 44 million ha of total rice area in the country, the upland rice occupies 7 million ha of which $75 \%$ is from eastern India only (Kar et al., 2004). Panigrahi and Panda (2003) developed a model for the prediction of optimal size of an on-farm reservoir (OFR) so as to provide supplemental irrigation to rice in monsoon season and pre-sowing irrigation to mustard in winter for a rainfed farming system of eastern India. Mahendrarajah et al., (1992) analyzed the optimization of monsoonal water storage tank for supplemental irrigation under double rice cropping in Sri Lanka. The interseasonal irrigation allocation of storage was solved by deterministic dynamic programming using simulated crop response function. Panigrahi et al., (2005) documented that construction of the on-farm reservoir (OFR) is an alternative for the storage of excess rainwater from the diked rice field during monsoon season followed by its reuse as supplemental irrigation to the rice in the same season and pre-sowing irrigation to mustard in the winter season. Prasad et al., (2011) formulated a weekly irrigation planning linear programming model for determining the optimal cropping pattern and reservoir water allocation for an existing storage based irrigation system in India. Vedula and Mujumdar (1992) formulated a model to obtain a steady state optimal reservoir operating policy for irrigation of multiple crops with stochastic inflows by first using dynamic programming (DP) to optimally allocate the available water among all crops within a given period, and then evaluated the system performance using stochastic dynamic programming (SDP) to optimize the benefits over a full year. Umamahesh and Sreenivasulu (1997) developed a two-phase stochastic dynamic programming model for optimal operation of irrigation reservoirs under a multicrop environment. The proposed model integrates reservoir release decisions with water allocation decisions. The water requirements of crops vary from period to period and are determined from the soil moisture balance equation taking into consideration the contribution of soil moisture and rainfall for the water requirements of the crops. The main objective of the present study is to determine the optimum size of the OFR using dynamic programming.

\section{Materials and Methods}

\section{Study area}

The site selected for the present study is the experimental farm of the Agricultural and Food Engineering Department of Indian Institute of Technology, Kharagpur in West Bengal state, India shown in Figure 1. It is located at Latitude $22^{\circ} 19^{\prime} \mathrm{N}$, Longitude $87^{\circ} 19^{\prime} \mathrm{E}$ and altitude $48 \mathrm{~m}$ above the mean sea level. The total field area is select as $800 \mathrm{~m}^{2}$ (including OFR area and crop area). Mean annual rainfall of the study area is about 1500 $\mathrm{mm}$, of which about $80 \%$ is received during kharif/monsoon season in between June and September. Sowing time of kharif and rabi crops is around $3^{\text {rd }}$ week of June and $3^{\text {rd }}$ week of October, respectively and harvesting time of kharif and rabi crops is nearly 1st week of October and $4^{\text {th }}$ week of December, respectively. The maximum and minimum temperatures during sowing to harvesting of the kharif and rabi season crops were nearly $34.7^{\circ} \mathrm{C}$ and $15^{\circ} \mathrm{C}$, respectively. Maximum and minimum relative humidity $(\mathrm{RH})$ during sowing to harvesting of the kharif and rabi season crops were nearly $98.2 \%$ and $51.9 \%$, respectively. The average wind velocity was $2.17 \mathrm{~km} / \mathrm{h}$ and $1.0 \mathrm{~km} / \mathrm{h}$ during $\mathrm{kharif}$ and $\mathrm{rabi}$ seasons, respectively. The average values of permanent wilting point, field capacity and saturation water content of the soil are 8, 18 
and $23 \%$, respectively. The dominant soil type in the study area is sandy loam (lightly textured), which is porous, very low water holding capacity and acidic in nature $(\mathrm{pH}$ ranging from 4.8 to 5.6) with poor organic matter content. The soil dries up quickly after cessation of rainfall.

\section{Dynamic programming model}

A deterministic dynamic programming optimization model was formulated for the OFR operation by integrating the dynamics of water availability in the OFR and the soil moisture content at the field level. The constraints conceptually consist of two components, the first component is reservoir level constraints dealing with supplemental irrigation decisions and its storage continuity related constraints, and the second are farm level constraints dealing with crop water allocation decisions and the soil moisture balance related constraints. In crop water allocation modeling, dated water production functions incorporate the effects of both the timing and quantities of water applications on crop yield (Doorenbos and Kassam, 1979).

Generally evapotranspiration is used as the water related independent variable. Stewart et al., (1974) proposedthe methodology for crop yield as a function of the ratio of actual evapotranspiration (AET) and potential evapotranspiration (PET) i.e., (AET/PET). A multiplicative dated water production function derived from sensitivity factors for water stress in various physiological crop growth stages was widely used in the past (Rao et al., 1990; Vedula and Mujumdar, 1992).

\section{Reservoir water balance}

This is governed by the reservoir storage continuity equation,

$$
S_{t+1}=S_{t}+S R_{t}+D R_{t}-E V P_{t}-S I_{t}(1)
$$

Where, $S_{t}=$ OFR storage at the beginning of period $\mathrm{t}\left(\mathrm{m}^{3}\right)$; $S R_{t}=$ inflow of surface runoff into the OFR during period $\mathrm{t}\left(\mathrm{m}^{3}\right)$;

$S I_{t}=$ supplemental irrigation applied to the crop in period $\mathrm{t}\left(\mathrm{m}^{3}\right) ; E V P_{t}=$ evaporation lose from the water surface of the OFR during period $\mathrm{t}\left(\mathrm{m}^{3}\right)$; and $D R_{t}=$ direct rainfall received over the OFR water surface in period $\mathrm{t}\left(\mathrm{m}^{3}\right)$.

\section{Soil moisture balance}

The general soil moisture balance equation based on mass-balance approach in the active and passive root-zone depths is:

\section{For active layer}

$S M_{t+1} R D_{t+1}=S M_{t} R D_{t}+P S M_{t}\left(R D_{t+1}-R D_{t}\right)+I R_{t}+R_{t}-A E T_{t}-P_{t}-S R_{t}$

\section{For passive layer}

$P S M_{t+1}\left(R D_{\text {max }}-R D_{t}\right)=P S M_{t}\left(R D_{\text {max }}-R D_{t}\right)+P_{t}-D P_{t}$

Where, ${ }^{S M_{t}}=$ root-zone soil moisture in period $\mathrm{t}(\mathrm{mm} / \mathrm{cm}) ;{ }^{R D_{t}}=$ root depth in period $\mathrm{t}(\mathrm{cm}) ;{ }^{R_{t}}=$ rainfall in period $\mathrm{t}(\mathrm{mm}) ;{ }^{P S M_{t}}=$ passive layer soil moisture in period $\mathrm{t}$ $(\mathrm{mm} / \mathrm{cm}) ;{ }^{P_{t}}=$ percolation in period $\mathrm{t}(\mathrm{mm})$; $D P_{t}=$ deep percolation in period $\mathrm{t}(\mathrm{mm})$ and $S R_{t}=$ surface runoff in time $\mathrm{t}(\mathrm{mm})$.

The available soil moisture in any time period $t$ is restricted to the maximum capacity of the soil,

$S M_{t} \leq S M_{\text {sat. }}$ (4)

Where, $S M_{\text {sat. }}=$ saturation soil moisture content. 
If, soil moisture content reaches up to the saturation level, then the equation (5) is valid for water balance calculation in the field.

$P D_{t+1}=P D_{t}+I R_{t}+R_{t}-A E T_{t}-P_{t}-S R$

Where, ${ }^{P D_{t}}=$ Depth of ponding in time period $\mathrm{t}(\mathrm{mm})$.

At the beginning of the season, the soil moisture in the entire root zone is assumed to be at its field capacity for the rice crop, due to pre-season rainfall.

\section{Crop root depth}

The depth of the active soil reservoir from which the crops extract water depends on the effective depth of root penetration into the soil. This depth increases with the crop growth and attains a maximum value by the end of the flowering stage for most of the crops. The following sine function developed by Borg and Grimes (1986) has been used to determine current tooting depth development with time $\left(\mathrm{RD}_{\mathrm{t}}\right)$ when maximum depth and maturity period of crops are known.

$$
R D_{t}=R D_{\text {max }}\left[0.5+0.5 \sin \left\{3.03\left(\frac{t}{t_{m}}\right)-1.47\right\}\right]
$$

Where, $\mathrm{t}=$ current day after planting; $\mathrm{t}_{\mathrm{m}}=$ days to maturity of crop; and $R D_{\max }=$ maximum rooting depth $(\mathrm{cm})$;

\section{Actual evapotranspiration}

Actual crop evapotranspiration depends on the evaporative demand of the atmosphere, the crop growth stage, and the available soil moisture in the root zone. For data unavailability reference evapotranspiration by Hargreaves method (Hargreaves et al., 1985) is calculated as:
$\mathrm{ET}_{0}=\frac{0.0023 R_{a}\left(T_{\text {mean }}+17.8\right) \sqrt{\left(T_{\text {max }}-T_{\text {min }}\right)}}{\lambda}$

Where, $\mathrm{ET}_{0}=$ reference evapotranspiration (mm/day); $T_{\max }=$ maximum air temperature $\left({ }^{0} \mathrm{C}\right) ; \quad{ }^{T_{\min }}=$ minimum air temperature $\left({ }^{0} \mathrm{C}\right)$; $T_{\text {mean }}=$ average air temperature $\left({ }^{0} \mathrm{C}\right) ; \lambda=$ latent heat of vaporization $\left(\mathrm{MJ} \mathrm{kg} \mathrm{kg}^{-1}\right)$; and $R_{a}=$ extraterrestrial radiation $\left(\mathrm{MJ} \mathrm{m} \mathrm{m}^{-2} \mathrm{~d}^{-1}\right.$ ) and is calculated as a function of day of year and latitude (Allen et al., 1998).

By using crop coefficient $\left(\mathrm{K}_{\mathrm{c}}\right)$ and reference evapotranspiration $\left(\mathrm{ET}_{0}\right)$, the potential evapotranspiration (PET) is computed as:

$P E T=K_{c} E T_{0}$

The actual evapotranspiration in relation to its potential rate is determined by considering whether the available soil water in the root zone is adequate or whether the crop will suffer from stress induced by water deficit. The actual evapotranspiration in each period is computed as follows:

\section{For rice crop}

$A E T_{t}=\left\{\begin{array}{cl}P E T_{t} & S M 1_{t}>(1-p) S M_{s a t} \\ \frac{S M_{t}}{S M_{s a t}} P E T_{t} & S M 1_{t} \leq(1-p) S M_{s a t}\end{array}\right.$

\section{For non-rice crop}

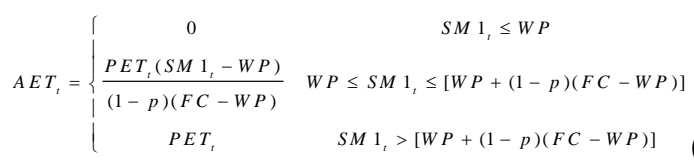

Where, WP $=$ wilting point $(\mathrm{mm} / \mathrm{cm}) ; \mathrm{FC}=$ field capacity $(\mathrm{mm} / \mathrm{cm}) ; M^{S a t}=$ saturated soil 
moisture content $(\mathrm{mm} / \mathrm{cm}) ; \mathrm{p}=$ crop water depletion factor and $S M 1_{t}=\left(S M{ }_{t} R D_{t}+R_{t}+I R_{t}\right) / R D_{t}$

\section{Supplemental irrigation}

The supplemental irrigation (IR) is applied once the soil moisture depleted beyond a predetermine level (p). The adopted approach in the present study is given below:

$I R_{t}=0$ If $\left(\left(S M_{t} R D_{t}+R_{t}\right) / R D_{t}\right) \geq(1-p) S M_{F C} \mathrm{f}$ or non-rice crop

$\left(\left(S M_{t} R D_{t}+R_{t}\right) / R D_{t}\right) \geq(1-p) S M_{s a t}$ For rice crop (11)

\section{Growth stages and decision intervals}

The objective function of the dynamic programming is formulated considering multiplicative form of dated production function when relative crop yield is function of relative evapotranspiration. The $\mathrm{N}$ growth stages of the crop correspond to $\mathrm{N}$ dynamic programming stages, when optimal irrigation water allocation (decision variable) among different growth stages is attempted by this procedure. The growth stages are of unequal durations of several weeks. Irrigation decisions, on the other hand, have to be made not only at small but also at regular intervals, to operate large systems effectively. For this reason, in this study, irrigation decisions are presumed to be made at weekly intervals and the weeks chosen to coincide with the standard weeks for convenience.

Each growth stage is divided into weekly intervals which coincide with the standard weeks and which also constitute the decision intervals. For this type of division of the growth stages it is possible that the first and last intervals in each stage may be of less than a week's duration, while all the intermediate intervals will be on seven days coinciding with the corresponding standard weeks. For the first and last intervals in each growth stage, the rainfall is estimated by proportioning the rainfall of that standard week in the ratio of the number of days in that interval to seven days.

\section{OFR capacity calculation}

The size of the OFR is important in capacity calculation. The OFR capacity must be enough to store the excess rainfall generated from the diked field. In the present study, it is considered that all the runoff generated from the field is stored in the OFR. Different dimensions of the bunds are shown in Figure 2. Top width $=30 \mathrm{~cm}$, Height $=30 \mathrm{~cm}$, Freeboard $=15 \mathrm{~cm}$, Side slope $=1: 1$ and Berm width $=30 \mathrm{~cm}$. Prismoidal formulas have been used to estimate the capacity of the OFR as follows:

$$
\begin{aligned}
& \text { Volume }=\left(\frac{D}{6}\right)+\left\{(\text { bottom width })^{2}+(\text { top width })^{2}+(\text { middle width })^{2}\right\} \\
& l_{t}=\sqrt{\left(F A \times \frac{S}{100}\right)}(12) \\
& l_{g}=l_{t}-2\left(2 h_{e} s_{2}+t_{w}+b_{w}\right)(13) \\
& l_{b}=\left(l_{t}-2\left(2 \times h_{e} \times s_{2}+t_{w}+b_{w}\right)-2 \times D \times s_{1}\right) \\
& ) \\
& V=\frac{D}{6}\left[\left(l_{b}\right)^{2}+\left(l_{b}+2 \times D \times s_{1}\right)^{2}+4\left(l_{b}+D \times s_{1}\right)^{2}\right](15)
\end{aligned}
$$

Where, $\mathrm{FA}=$ farm area $\left(\mathrm{m}^{2}\right) ; \mathrm{S}=\mathrm{OFR}$ size, $\%$ of farm area; $\mathrm{V}=$ volume of water in OFR below the field level $\left(\mathrm{m}^{3}\right) ; 1_{t}=$ width of the square OFR at the outer end of the embankment, $\mathrm{m} ; 1_{\mathrm{g}}=$ width of the square OFR at ground level, $\mathrm{m} ; \mathrm{l}_{\mathrm{b}}=$ bottom width of the OFR, $\mathrm{m} ; \mathrm{s}_{1}=$ side slope of the OFR, $\% ; \mathrm{s}_{2}=$ side slope of the embankment, \%; $d=$ depth of 
water below the ground level of the OFR, m; $\mathrm{t}_{\mathrm{w}}=$ top width of the embankment, $\mathrm{m} ; \mathrm{b}_{\mathrm{w}}=$ berm width given at the ground level, $m ; h_{e}=$ height of the embankment, $\mathrm{m} ; \mathrm{D}=$ depth of the OFR, m;

\section{Results and Discussion}

The dynamic programming reservoir operation model was run using 30 years (1985-2014) of input data and every year it was run from 5 to $12 \%$ OFR sizes (for the field area of $800 \mathrm{~m}^{2}$ ) with an increment of $0.1 \%$. At each time period, the model output gives decision for each crop at the OFR level (supplemental irrigation, OFR storage, and evaporation losses); and at the farm level (water allocation, soil moisture status, actual evapotranspiration, deep percolation, and surface runoff).

\section{Model output for $9 \%$ OFR area (2014)}

Output from the developed model (weekly crop water allocation and weekly crop response pattern) using dynamic programming technique for the year 2014 is pond area of $9 \%$ of total field area. Supplemental irrigation at $10 \%$ soil water depletion (from saturation) for rice crop and mustard (from field capacity) is shown in Figure 3. In rice crop, supplemental irrigation is not needed because of uniform distribution of rainwater throughout the cropping season.

But in case of mustard four supplemental irrigation was needed due lack of soil moisture in the soil. Initial soil moisture content of the field at the starting of rice crop was taken as $2.0 \mathrm{~mm} / \mathrm{cm}$. In the initial stage of rice crop there was a requirement of supplemental irrigation due to lack of soil moisture in the field. But, as initial storage of OFR was taken as zero, allocation of water in initial stage of rice crop was zero. For kharif season, water deficit problem was minimal as sufficient amount of rainfall was received during monsoon season. The results obtained for initial soil moisture and AET/PET, surface runoff, deep percolation for each crop for each time period from the OFR operation model from the objective function is illustrated in Figure 4-6. These figures provide an overview of soil moisture status at the crop root zone and crop response (AET/PET) patterns, deep percolation, surface runoff of rice and mustard crops grown in two seasons, during various stages of crop growth.

It can be observed that for two crops water allocation are different, resulting in difference of the crop response pattern.

It was observed that in growth stage which has less crop yield response factor, water allocation was minimum. In initial stage of mustard crop there was a need of supplemental irrigation but due to less yield response factor in that stage, irrigation allocation was zero. In addition, it is also noticed that due to lack of storage water, maximum water allocation for mustard crop is in crop development and grain formation stage.

\section{Determination of OFR size under different soil water depletion factor for rice - mustard in different years}

The model was run to calculate OFR size under rice-mustard cropping sequence in 800 $\mathrm{m}^{2}$ field areas and OFR depth was maintained as $2.5 \mathrm{~m}$. In case of rice crop, $10 \%$ and $15 \%$ soil water depletion from saturation was considered. Whereas for mustard crop, $10 \%$ and $15 \%$ soil water depletion from field capacity was considered. Figure 7 and 8 represents the variation of optimum size of OFR area $(\%)$ and relative yield of rice and mustard crops in different years. In case of $10 \%$ soil water depletion for rice and mustard crops, optimum OFR size varies from $5.35 \%$ to $9.85 \%$, relative yield of rice varies from 0.65 to 0.88 and relative yield of mustard varies from 0.85 to 0.94 . 
Fig.1 Location map of the study area

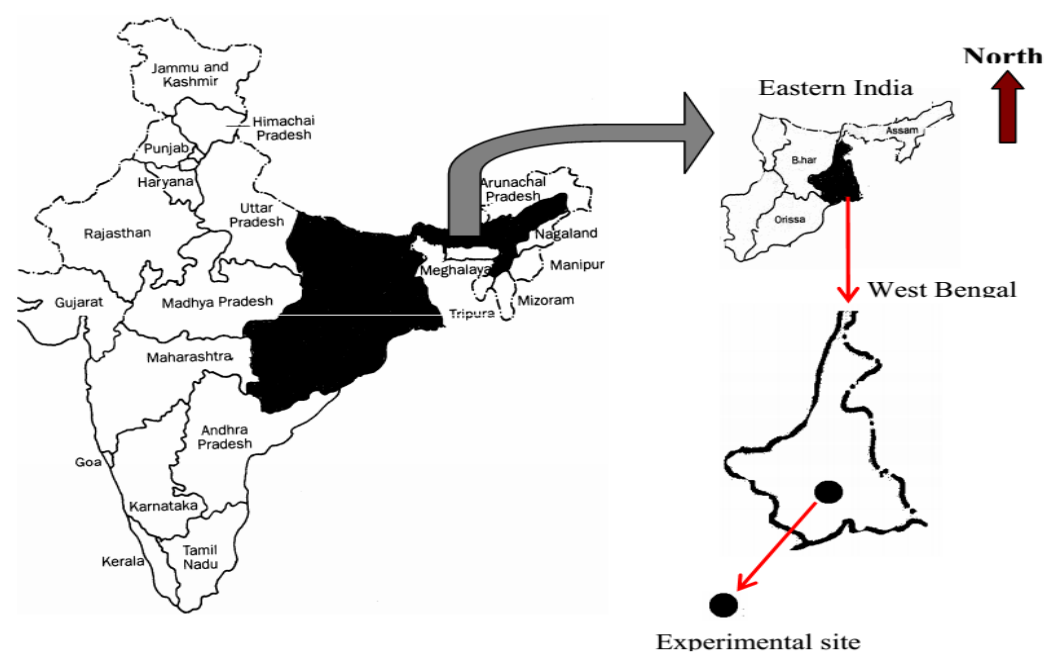

Source: Sahoo (2010).

Fig.2 Different dimension of the OFR

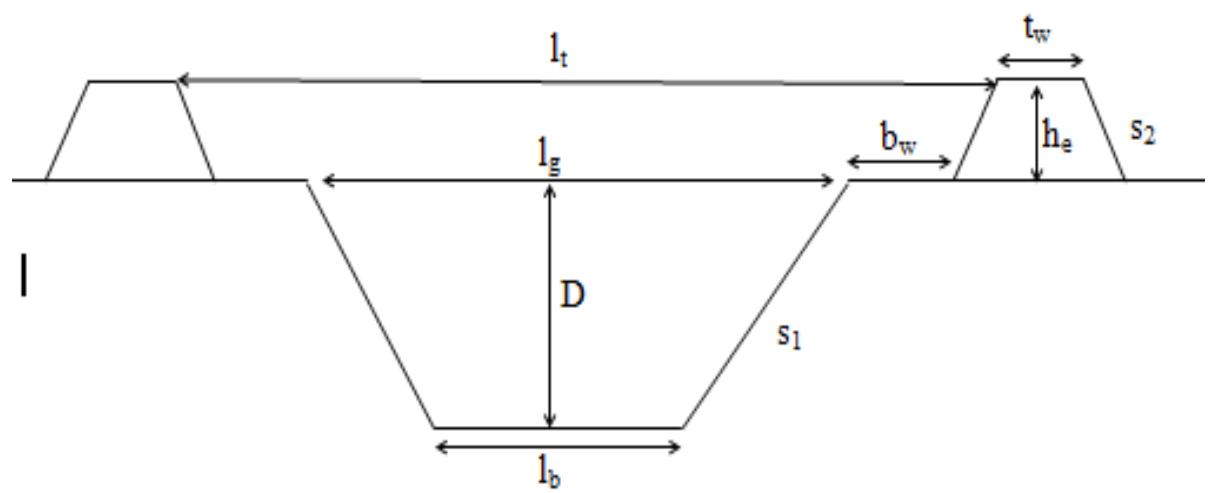

Fig.3 Supplemental irrigation allocation from the reservoir operational model results for 9\% OFR size in 2014

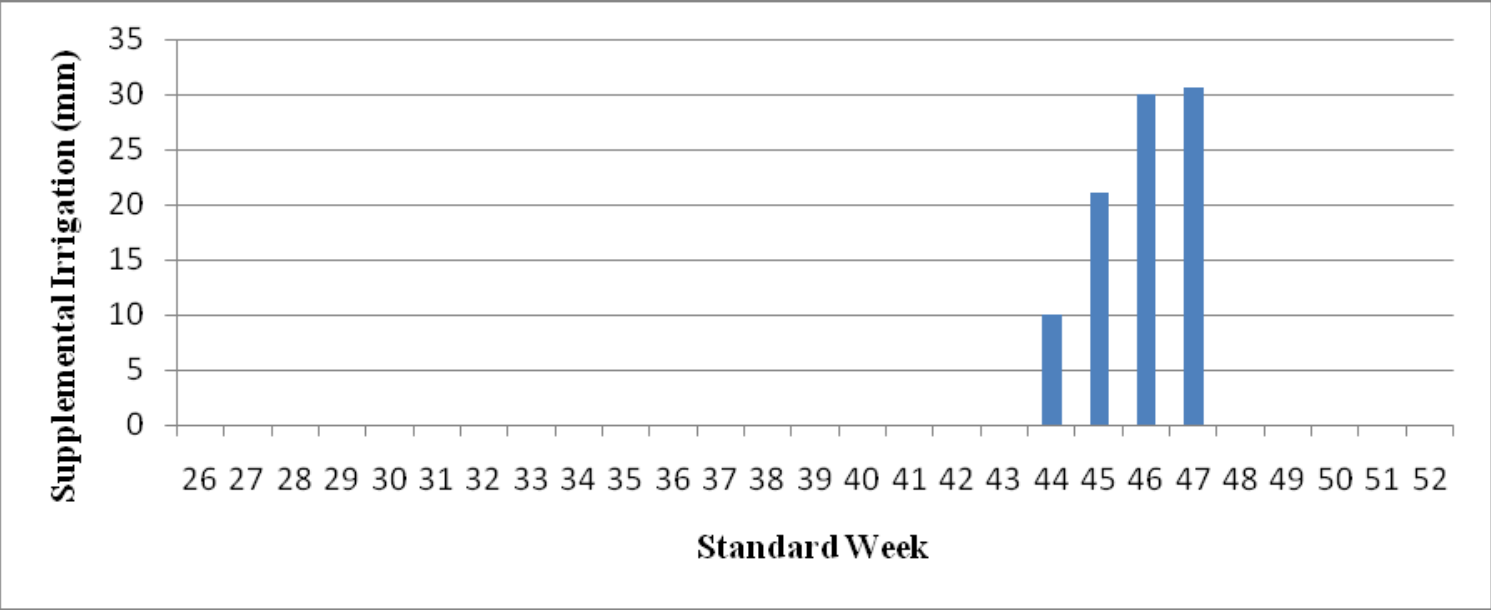


Fig.4 The OFR operation model results for kharif rice at 9\% OFR size in 2014, showing weekly (i) Soil moisturestatus; (ii) Relative evapotranspiration
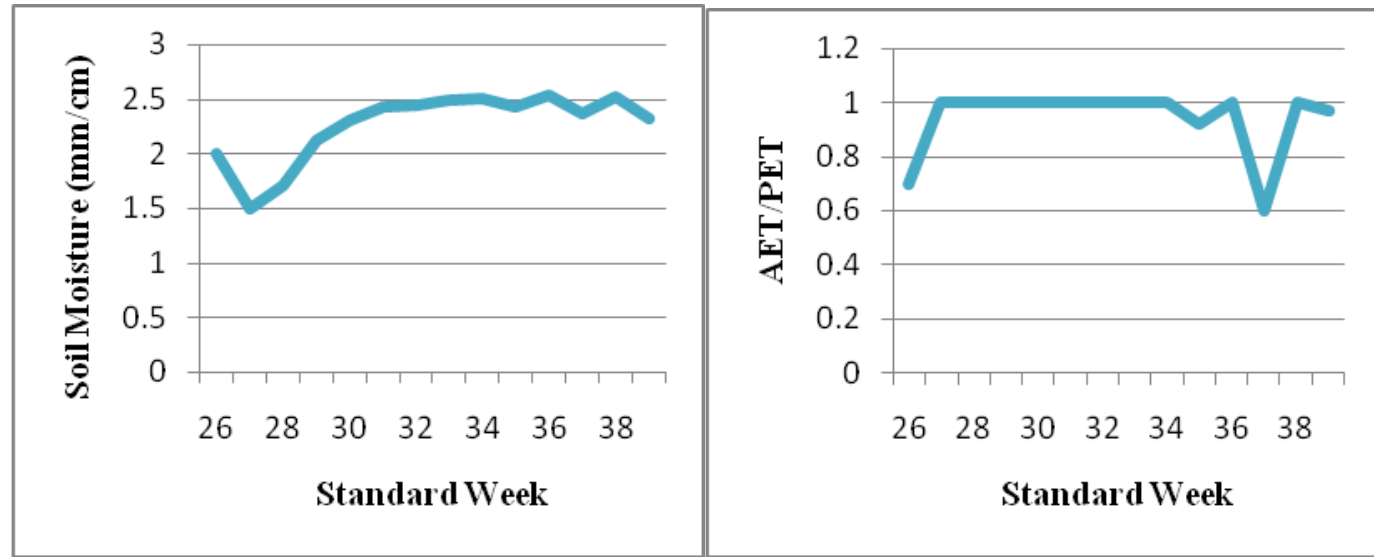

Fig.5 OFR operation model results for rice crop for 9\% OFR size in 2014, showing weekly (i) Deep percolation; (ii) Surface runoff
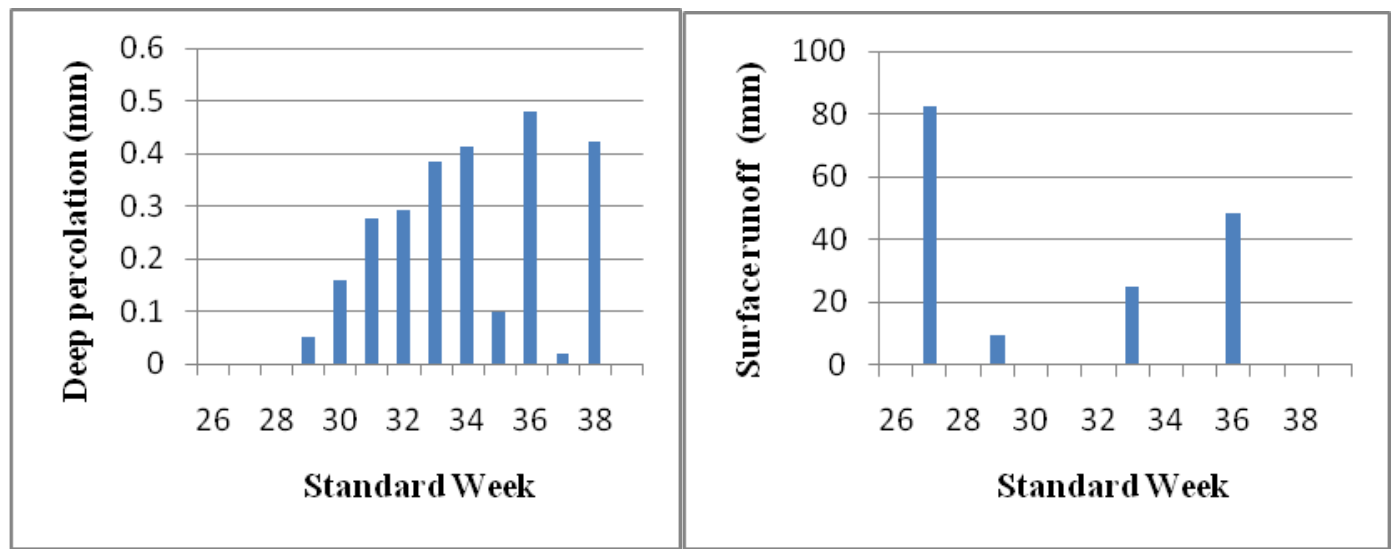

Fig.6 The OFR operation model results for mustard at 9\% OFR size in 2014, showing weekly (i) Soil moisture status; and (ii) Relative evapotranspiration
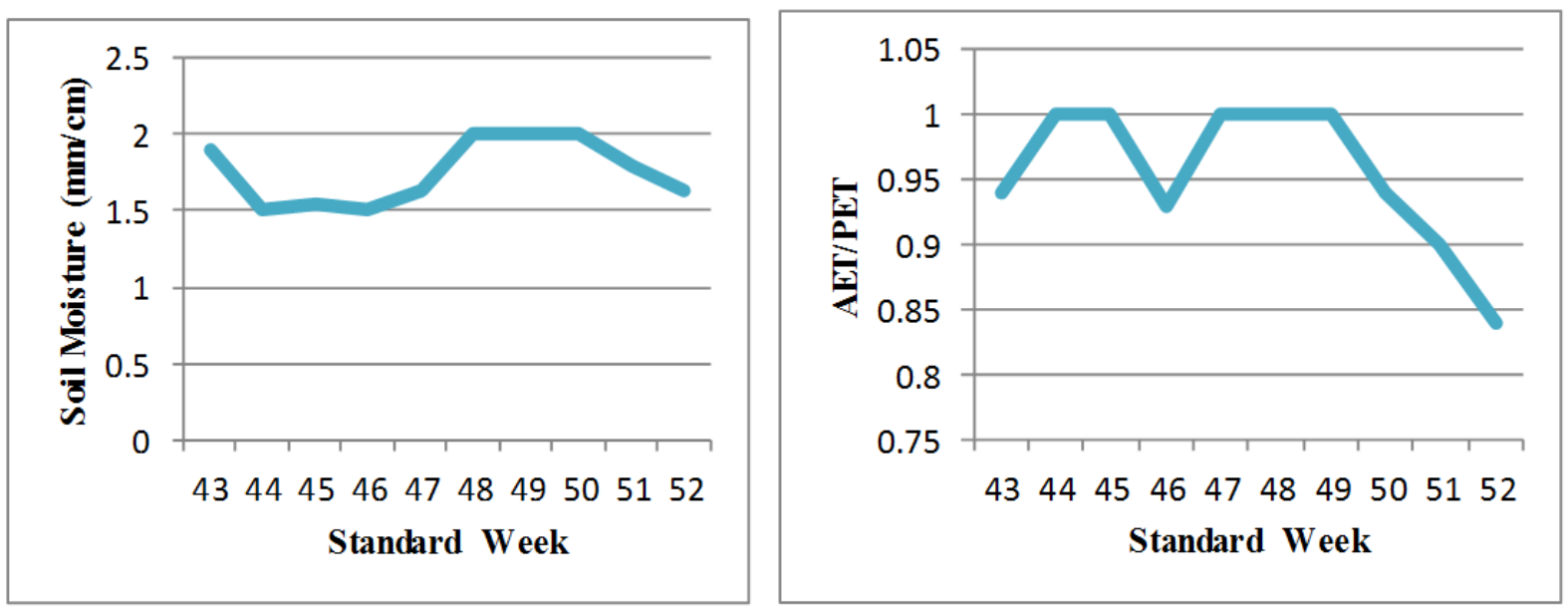
Fig.7 Variations in the OFR size, relative yield of rice (10\% soil moisture depletion from saturation), and mustard (10\% soil moisture depletion from field capacity) to maximize net annual return during $1985-2014$

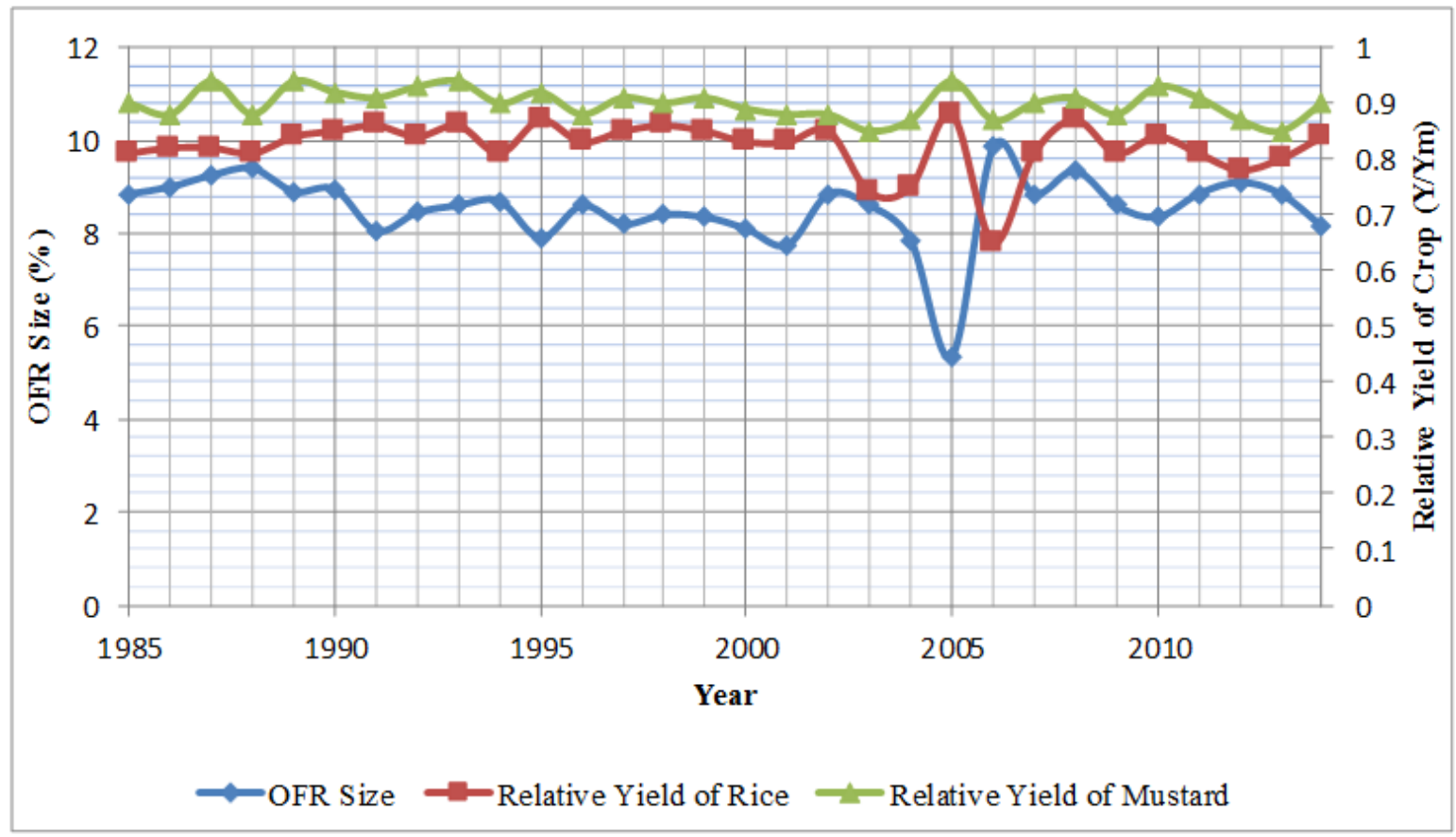

Fig.8 Model results for maximum return condition in different years for rice crop (R) 15\% soil water depletion from saturation and mustard crop (M) 15\% soil water depletion from field capacity

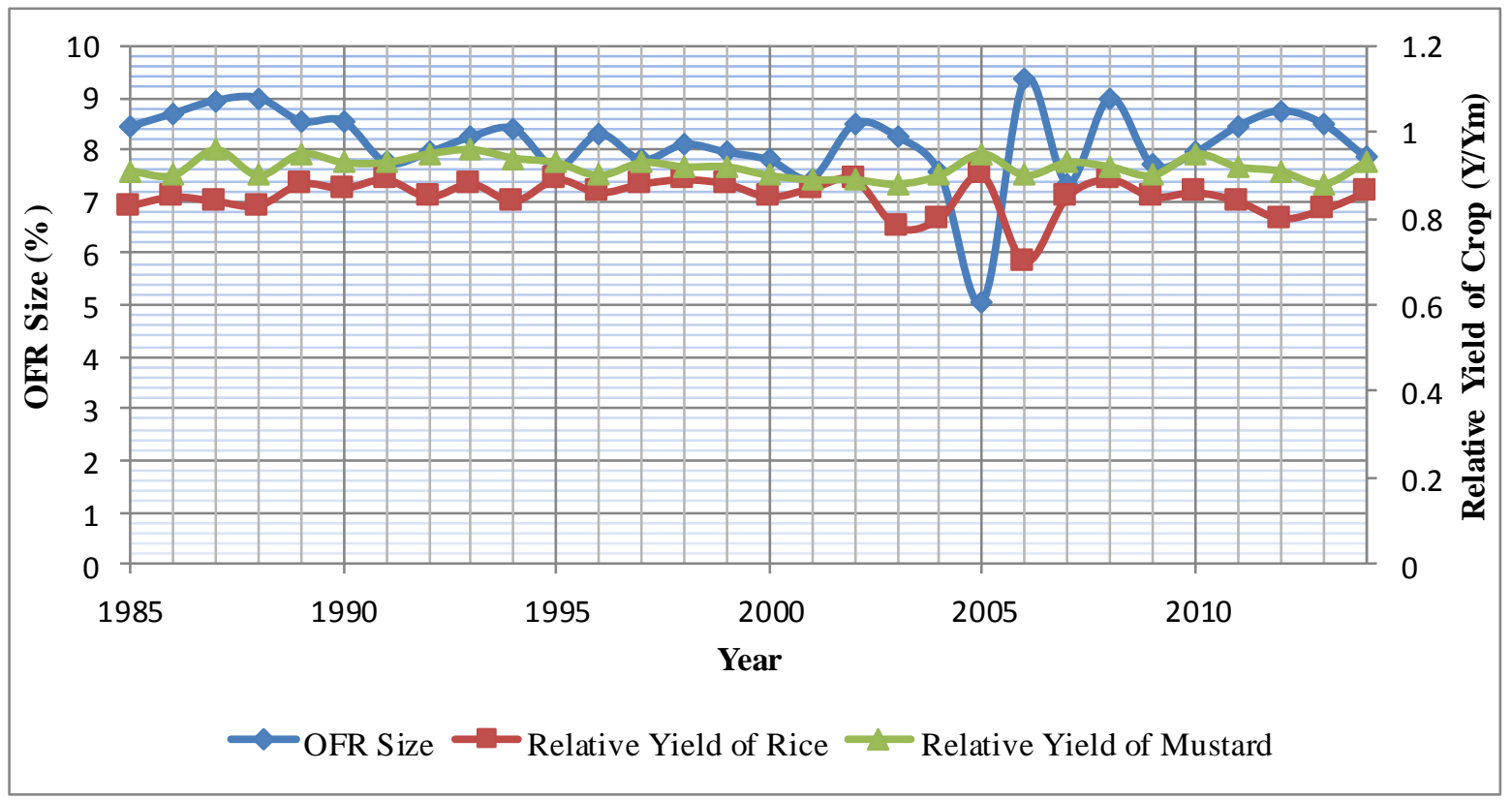


Fig.9 Variations in the OFR size and relative yield of rice at 10\% soil moisture depletion from saturation to maximize net seasonal return during $1985-2014$

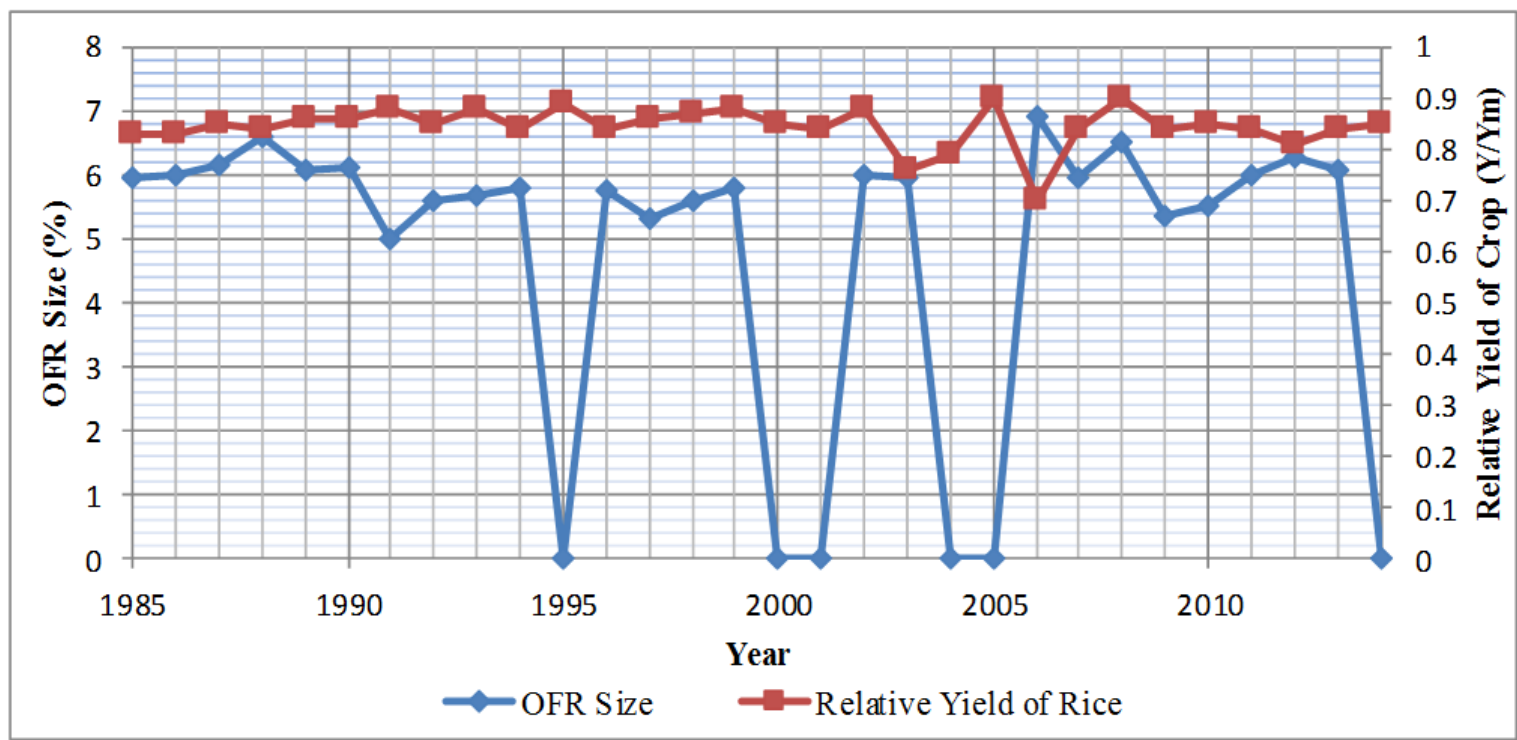

Fig.10 Variations in the OFR size and relative yield of rice $(\mathrm{R})$ at $15 \%$ soil moisture depletion from saturation to maximize net seasonal return during $1985-2014$

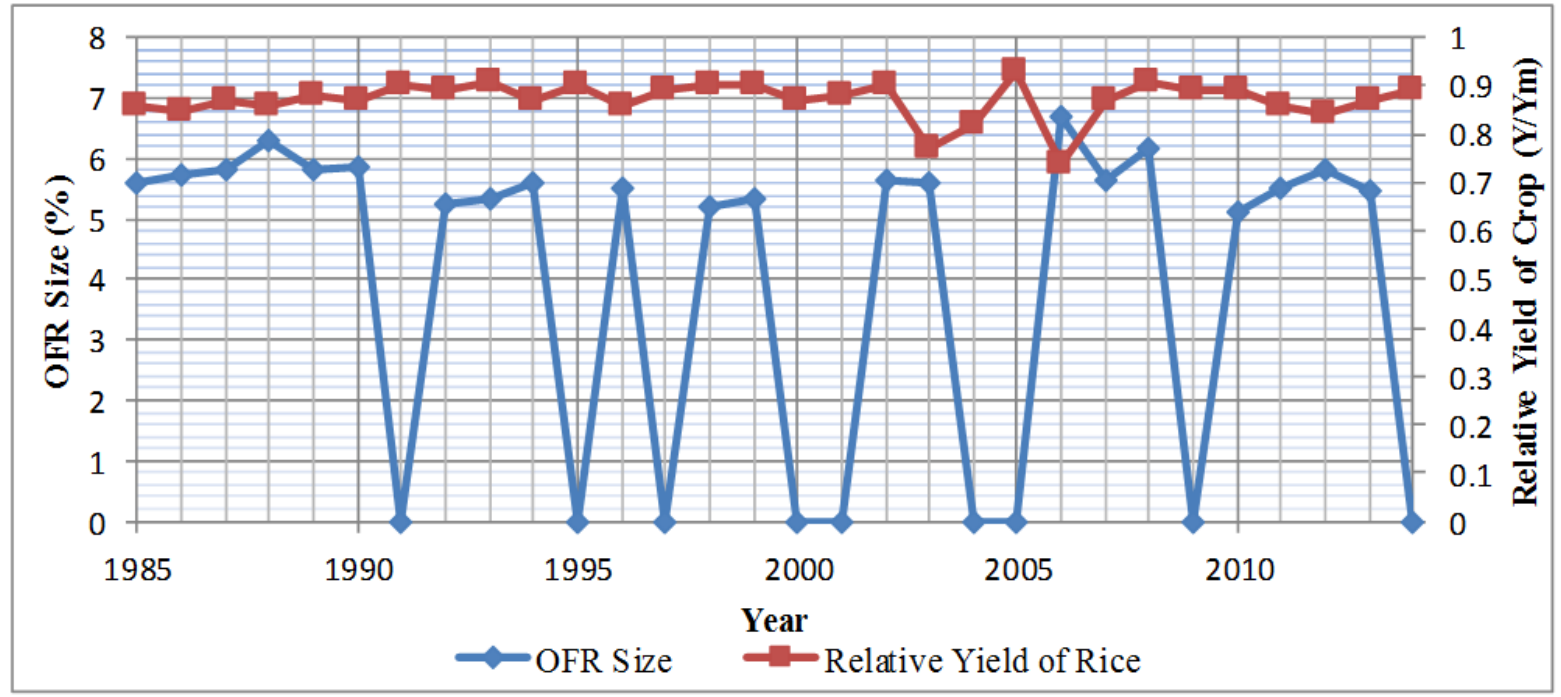

In case of $15 \%$ soil water depletion for rice and mustard crops, optimum OFR size varies from $5.05 \%$ to $9.35 \%$, relative yield of rice varies from 0.70 to 0.90 and relative yield of mustard varies from 0.88 to 0.96 . The OFR size was higher and relative yield of rice and mustard was low in case of $10 \%$ depletion than in $15 \%$ depletion.

\section{Determination of OFR size under different} soil water depletion factor for rice

The model was run to calculate OFR size under rice-mustard cropping sequence in 800 $\mathrm{m}^{2}$ field areas and OFR depth was maintained as $2.5 \mathrm{~m}$. For rice crop $10 \%$ and $15 \%$ soil water depletion from saturation was 
considered. Figures 9 and 10 represent the variation of optimum size OFR area (\%) and relative yield of rice crop in different years. In case of $10 \%$ soil water depletion from saturation for rice crop, optimum OFR size varies from $0.0 \%$ to $6.90 \%$, relative yield of rice varies from 0.70 to 0.90 . In case of $15 \%$ soil water depletion from saturation for rice crop, optimum OFR size varies from $0.0 \%$ to $6.70 \%$, relative yield of rice varies from 0.74 to 0.93 . The OFR size was higher and relative yield of rice crop was low in case of $10 \%$ depletion than in $15 \%$ depletion.

Present study indicates that the optimum size of the OFR varies with the number of crops grown in various cropping seasons in a year. It is less when only rice crop is grown as compared to rice followed by mustard crop in a year. The optimum size of the OFR is decreasing with the increase in soil moisture depletion factor. For $10 \%$ soil water depletion for rice (from saturation) and mustard (from field capacity) crops, the optimum size of OFR varied from $5.35 \%$ to $9.85 \%$. Similarly, for $15 \%$ soil water depletion it varied from $5.05 \%$ to $9.35 \%$. If only rice crop is grown, the optimum size of OFR for $10 \%$ soil water depletion varied from $0.00 \%$ to $6.90 \%$, whereas for $15 \%$ soil water depletion it varied from $0.00 \%$ to $6.70 \%$. Similarly, relative yield for $10 \%$ and $15 \%$ soil water depletion varied from 0.70 to 0.90 and 0.74 to 0.93 . If a year from a particular size of OFR the return of the crop is less than the return came from no OFR condition then it show no OFR required at that year.

\section{References}

Allen, R. G., Pereira, L. S., Raes, D., and Smith, M. (1998). Crop evapotranspiration: Guidelines for computing crop water requirements. FAO Irrigation and Drainage Paper No. 56, FAO, Rome.
Borg, H., and Grimes, D.W. (1986). Depth development of roots with time- An empirical Description. Transactions on ASAE, 29: 194-197.

Doorenbos, J., and Kassam, A. H. (1979). Yield response to water. FAO Irrigation and Drainage, Paper 33, Food and Agricultural Organization, Rome, Italy.

Hargreaves, G. L., Hargreaves, G.H., and Riley, J.P. (1985). Agricultural benefits for Senegal River basin. Journal of irrigation and Drainage Engineering, 111(2): 113-124.

Islam, M.T., Saleh, A.F.M., and Bhuiyan, S.I. (1998). Agro-hydrologic and economic analyses of onfarm reservoirs for drought alleviation in rainfed rice lands of northwest Bangladesh. Rural and Environmental Engineering, 35: 15-26.

Kar, G., Singh, R., and Verma, H.N. (2004). Alternate cropping strategies for assured and efficient in upland rainfed rice areas of eastern India based on rainfall analysis. Agricultural Water Management, 67(1): 47-62.

Mahendrarajah, S., War, P.G., and Jakeman, A.J.J. (1992). Optimal extraction of small-scale surface storage in Asia. Water Resources Research, ASCE, 28(5): 1207-1220.

Panigrahi, B., and Panda, S.N. (2003). Optimal sizing of on-farm reservoirs for supplemental irrigation. Journal of Irrigation and Drainage Engineering, ASCE, 129(2): 117-128.

Panigrahi, B., Panda, S.N., and Agrawal, A. (2005). Water balance simulation and economic analysis for optimal size of on-farm reservoir. Water Resources Management, 19(3): 233-250.

Panigrahi, B., Panda, S.N., and Mal, B.C. (2007). Rainwater conservation and recycling by optimal size on-farm reservoir. Journal of Recourses, Conservation and Recycling, 50: 459 474. 
Prasad, A.S., Umamahesh, N.V., and Viswanath, G.K. (2011). Optimal irrigation planning model for an existing storage based irrigation system in India. Irrigation and Drainage Systems, 25(1): 19-38.

Rao, N.H., Sarma, P.B.S., and Chander, S. (1990). Optimal multicrop allocation of seasonal and intra-seasonal irrigation water. Water Resources Research, ASCE, 26(4): 551-559.

Sahoo, B.C. (2010). Root-zone water balance simulation for optimal sizing of on-farm pond for rice substitution in rainfed uplands. Ph.D. Thesis. Indian Institute of Technology, Kharagpur, India.

Srivastava, R.C. (2001). Methodology for design of water harvesting system for high rainfall areas. Agricultural Water Management, 47(1): 37-53.

Stewart, J.I., Hagan, R.M., and Pruitt, W.O. (1974). Functions to predict optimal irrigation programs. Journal of Irrigation and Drainage Engineering, ASCE, 100(2): 179-199.

Umamahesh, N. V., and Sreenivasulu, P. (1997). Two-phase dynamic programming model for optimal operation of irrigation reservoir. Water Resources Management, 11: 395- 406.

Vedula, S., and Mujumdar, P.P. (1992). Optimal Reservoir Operation for Irrigation of Multiple Crops. Water Resources Research, ASCE, 28(1): 1-9.

\section{How to cite this article:}

Mithlesh Kumar, SanjeebPaul, Sudhindra N. Panda and Panigrahi, B. 2018. Optimum Size of On-Farm Reservoir using Dynamic Programming. Int.J.Curr.Microbiol.App.Sci. 7(03): 334345. doi: https://doi.org/10.20546/ijcmas.2018.703.039 